\title{
Snowman-shaped heart in an adult patient
}

\section{Corazón en forma de muñeco de nieve en un paciente adulto}

\author{
Zahra Khajali', Leili Pourafkari, ${ }^{1,2}$ y Nader D. Nader ${ }^{2 *}$
}

${ }^{1}$ Cardiology Department, Rajaei Cardiovascular Medical and Research Center, Iran University of Medical Sciences, Tehran, Iran; ${ }^{2}$ Department of Anesthesiology, University at Buffalo, Buffalo, Nueva York, E.E.U.U

A 27-year-old woman presented with dyspnea and fatigue. She was an immigrant, who had received little medical care. On examination, she was cyanotic with $\mathrm{O}_{2}$-saturation of $75 \%$ at room air and had clubbing. Chest-X-ray showed increased pulmonary vascular markings and widening of the superior mediastinum and a classic "snowman" or "cottage loaf" appearance, indicative of supra-cardiac total anomalous pulmonary venous return (TAPVR) (Fig. 1A). In transthoracic echocardiography, right-sided chambers enlargement and atrial septal defect were present. The patient had obligatory right to left shunt since none of the pulmonary veins drained to the left atrium, and accordingly mixed oxygenated and non-oxygenated blood passed from right atrium to left atrium through atrial septal defect without which survival would not be possible for the patient. Pulmonary pressure was estimated $45 \mathrm{mmHg}$ by echocardiography. TAPVR is characterized by anomalous drainage of all four pulmonary veins into the right atrium. As such, survival is dependent on the right to left shunt through the interatrial septum. Survival to adulthood in unrepaired patients is extremely rare ${ }^{1}$. In supra-cardiac form, the confluence of pulmonary veins behind the heart drains to an ascending vertical vein

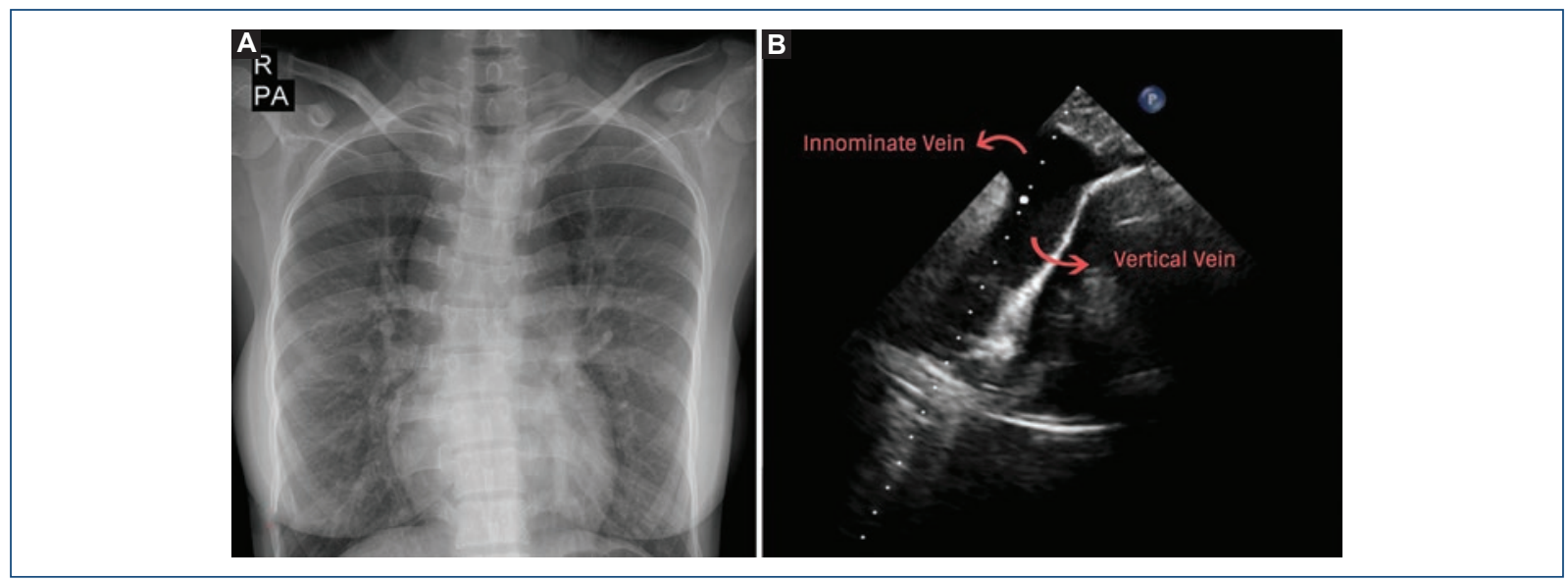

Figure 1. A: Chest X-ray showing snowman-shaped heart. B: Transthoracic echocardiogram from the suprasternal window showing vertical vein draining into the innominate vein. PA: posterioanterior projection; R: right side.

\section{Correspondencia:}

*Nader D. Nader

E-mail: nadernd@gmail.com
Fecha de recepción: 27-01-2019

Fecha de aceptación: 19-06-2019

DOI: 10.24875/ACM.19000050
Disponible en internet: 15-07-2019 Arch Cardiol Mex. 2019;89(4):401-402

www.archivoscardiologia.com

1405-9940/C 2019 Instituto Nacional de Cardiología Ignacio Chávez. Publicado por Permanyer. Este es un artículo open access bajo la licencia CC BY-NC-ND (http://creativecommons.org/licenses/by-nc-nd/4.0/). 
(VV) which forms the right of the upper mediastinum. VV drains into the innominate vein (Fig. 1B) and eventually to the dilated right superior vena cava, which altogether make the head of the snowman. The lower part of snowman is made up of enlarged right-sided chambers. We recommended the right heart catheterization and corrective surgery for the patient. In such patients, surgery would be in the form of restoration of pulmonary vein drainage to left atrium and closure of the atrial septal defect. Unfortunately, the patient refused treatment and was lost to follow-up.

\section{Supplementary data}

Supplementary data are available at Revista Archivos de Cardiología de México online (http://www.archivoscardiologia.com/index.php\#). These data are provided by the corresponding author and published online for the benefit of the reader. The contents of supplementary data are the sole responsibility of the authors.

\section{Conflicts of interest}

The authors declare to conflicts of interest.

\section{Funding}

None.

\section{Ethical disclosures}

Protection of human and animal subjects. The authors declare that the procedures followed were in accordance with the regulations of the relevant clinical research ethics committee and with those of the Code of Ethics of the World Medical Association (Declaration of Helsinki).

Confidentiality of data. The authors declare that they have followed the protocols of their work center on the publication of patient data.

Right to privacy and informed consent. The authors have obtained the written informed consent of the patients or subjects mentioned in the article. The corresponding author is in possession of this document.

\section{Reference}

1. Talib N, Sayuti KA, Abdullah MS, Mohd Zain MR. Beating the odds: a rare case of supracardiac total anomalous pulmonary venous return (TAPVR) in an adult patient. BMJ Case Rep. 2018;2018:bcr-2017-221074. 